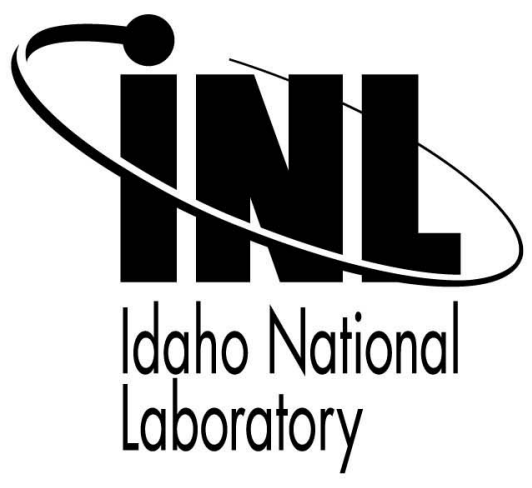

\title{
Supporting Multiple Cognitive Processing Styles Using Tailored Support Systems
}

\section{Joint $8^{\text {th }}$ IEEE HFPP $/ 13^{\text {th }}$ HPRCT}

Tuan Q. Tran

Karen M. Feigh

Amy R. Pritchett

\section{August 2007}

This is a preprint of a paper intended for publication in a journal or proceedings. Since changes may be made before publication, this preprint should not be cited or reproduced without permission of the author. This document was prepared as an account of work sponsored by an agency of the United States Government. Neither the United States Government nor any agency thereof, or any of their employees, makes any warranty, expressed or implied, or assumes any legal liability or responsibility for any third party's use, or the results of such use, of any information, apparatus, product or process disclosed in this report, or represents that its use by such third party would not infringe privately owned rights. The views expressed in this paper are not necessarily those of the United States Government or the sponsoring agency. 


\title{
Supporting Multiple Cognitive Processing Styles Using Tailored Support Systems
}

\author{
Tuan Q. Tran ${ }^{(1)}$, Karen M. Feigh ${ }^{(2)}$, and Amy R. Pritchett ${ }^{(2)}$ \\ (1) Human Factors and I\&C Department, Idaho National Laboratory, Idaho Falls, Idaho, USA, tuan.tran@inl.gov \\ ${ }^{(2)}$ Georgia Institute of Technology, Cognitive Engineering Center, Atlanta, Georgia, USA, \\ kfeigh@isye.gatech.edu, amy.pritchett@ae.gatech.edu
}

\begin{abstract}
According to theories of cognitive processing style or cognitive control mode, human performance is more effective when an individual's cognitive state (e.g., intuition/scramble vs. deliberate/strategic) matches his/her ecological constraints or context (e.g., utilize intuition to strive for a "good-enough" response instead of deliberating for the "best" response under high time pressure). Illmapping between cognitive state and ecolgoical constraints are believed to lead to degraded task performance. Consequently, incorporating support systems which are designed to specifically address multiple cognitive and functional states e.g., high workload, stress, boredom, and initiate appropriate mitigation strategies (e.g., reduce information load) is essential to reduce plant risk. Utilizing the concept of Cognitive Control Models, this paper will discuss the importance of tailoring support systems to match an operator's cognitive state, and will further discuss the importance of these ecological constraints in selecting and implementing mitigation strategies for safe and effective system performance. An example from the nuclear power plant industry illustrating how a support system might be tailored to support different cognitive states is included.
\end{abstract}

\section{INTRODUCTION}

Decision-making in the nuclear control room can be characterized as having high levels of information uncertainty, high risk, dynamic environment cues, shifting or competing goals, and significant time stress [1]. At times, control room operators continuously and proactively monitor, assess, and anticipate plant conditions, in addition to being involved in plant maintenance support roles. At other times, the operator is reacting such as when resolving plant disturbances. Thus, illustrating a roller-coaster of different mental and emotional states an operator is cycling through. The continuous transition among different mental states creates challenges for system designers to provide information that is suitable (e.g, right type and amount of information) for the operator at different mental states to foster safe and efficient performance.

This paper will begin by describing the Cognitive Control Model (COCOM) and its major assumptions. It will then discuss how using the COCOM's model of control can inform the design of support systems to be sensitive to operator's transient mental states. While, the design recommendations in this paper can be generalize to either decision support system or alerting system, the provided example describe later in this paper will focus on alerting system.

\section{COGNITIVE CONTROL MODES AND PROCESSING CHARACTERISTICS}

\section{A. Cognitive Control Modes}

A number of theoretical models [e.g., 2, 3, 4, 5] have been developed to describe how operators make decisions in complex and dynamic environment. The majority of these models recognize that an operator's cognitive state or mode is not static, but rather transient. Further they have postulated that the cognitive states exist within a continuum. The continuum is based upon the concept of control, with control being described as "necessary to organize the actions within the person's time horizon" [3, p155]. Accordingly a person's cognitive state results from the level of control being exerted, different levels of control naturally lead to different cognitive states. Information organization or manipulation takes certain amount of time and effort thus the level of cognitive control is heavily dictated by ecological constraints, such as time and resource availability. Ecological constraints encompass both the external environmental demands (e.g., available time to response, stress, information availability and reliability) as well individual's competence (e.g., knowledge, experience, motivation).

The ecological constraints affect on level of control modes have a direct influence on operators adopting different reasoning, problem-solving, and decisionmaking strategies to cope with the situational demands. For example, high information load, low event/time horizon conditions, incomplete information, or low motivation would lead operators to use quick intuition information processing (i.e., environmental cues are simply sense and responded to) in place of slower analytical information processing (i.e., environmental cues are assessed, hypothesized, consider plans of actions) [6, 7]. Accordingly, transition between cognitive modes is dependent on the ecological demands as well as operator's abilities and skills (e.g., identify correct cognitive mode to cope with such demands).

An underlying assumption among these theoretical models is that improved performance depends on 
successful mapping between operator's cognitive mode and ecological constraints. For example, deciding on a good-enough solution to a problem under high time pressure is a more effective strategy than deliberating for an optimal solution. Conversely, sub-optimal performance occurs when the operator's cognitive mode is ill-mapped in relation to the contextual constraints; for example, operator deliberating on a course of action when the situation calls for an immediate response [2] (See Figure 1).

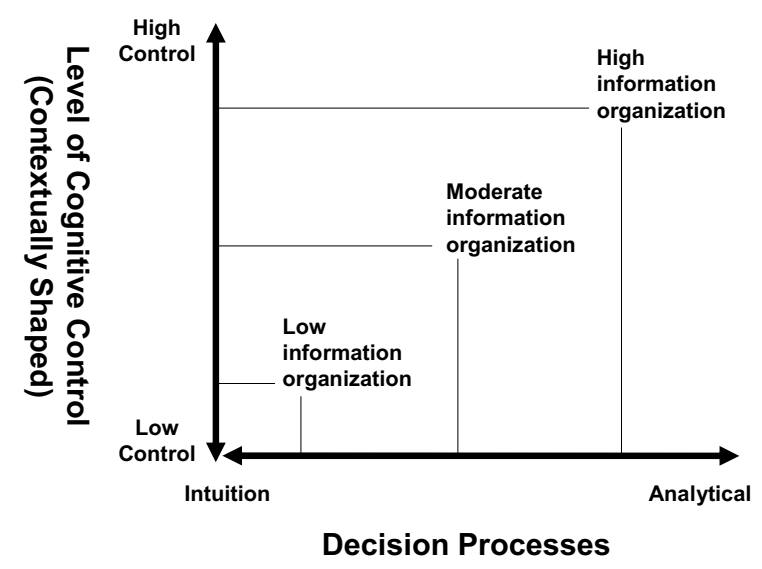

Figure 1. Mapping Between Level of Cognitive Control and Decision Processes.

Thus, operator performances can be improved by the use of a system that is flexible enough to accommodate a range of control modes and tailored to the operator's operational control mode in providing appropriate type and amount of information. For instance, using the framework provided by the control modes it may not always be appropriate for a system to present a large wealth of information but rather for certain control modes it may be more appropriate to, highlight critical cues when the context requires a timely operator response. In designing a flexible and multi-modal support system, it is critical to first understand the information processes under different cognitive control modes. To achieve this objective, this paper will use the "Contextual Control Mode (COCOM)" of Erik Hollnagel $[3,8]$ in describing how ecological demands can direct individual's thoughts and actions.

\section{B. Contextual Control Mode (COCOM) Characteristics}

Contextual Control Mode (COCOM) [3,8] framework describes four characteristics control modes:
Scrambled Control: "choice of next action is in practice unpredictable or haphazard. Scrambled control characterizes a situation where there is little or no thinking involved in choosing what to do... extreme case of scrambled control is the state of momentary panic.." (p155).

Opportunistic Control: "the next action is determined by the salient features of the current context rather than on more stable intentions or goals... the person will often be driven either by the perceptually dominant features of the interface or by those which is due to experience..” (p156).

Tactical Control: "performance is based on planning, hence more or less follows a known procedure or rule. If the plan is a frequently use one, performance corresponding to tactical control may seem as if it was based on a procedural prototype - corresponding to e.g., rule-based.." (p156)

Strategic Control: "the person considers the global context, thus using a wider time horizon and looking ahead at the higher level goals.." (p156)

While the COCOM presents four characteristic control modes, our discussion in this paper will be on opportunistic, tactical, and strategic control modes. The absence of the scrambled control mode in this paper reflects our assumptions that nuclear control room activities are heavily proceduralized and operated by highly skill individuals, who should be trained enough to recognize when they get into a situation where they take on the scrambled mode, and not seek to operate in it.

COCOM provides a high-level understanding of what conditions would cause an operator to transition from one control mode to another, as well as operator's performance characteristics under different control modes based upon ecological constraints (See Table 1). For instance, when an operator's evaluation of events is poor given the lack of information or unavailability, or if an operators understanding of a procedure due to poor knowledge or skills (because of rarity of a specific plant disturbance occurrence) operator may adopt a more opportunistic control mode. Conversely, if the available time to respond is adequate and the event horizon is extended, an operator would be steered towards a more strategic control mode. In a more strategic control mode, operators would have sufficient time and effort to attend to several goals and plan a course of action in a predictive manner. 
TABLE 1. PERFORMANCE CHARACTERISTICS UNDER COCOM (REPRINTED FROM REFERENCES [3, p193]

\begin{tabular}{|l|l|l|l|}
\hline $\begin{array}{l}\text { Ecological } \\
\text { Constraints }\end{array}$ & $\begin{array}{l}\text { Opportunistic } \\
\text { Control }\end{array}$ & $\begin{array}{c}\text { Tactical } \\
\text { Control }\end{array}$ & $\begin{array}{c}\text { Strategic } \\
\text { Control }\end{array}$ \\
\hline $\begin{array}{l}\text { Number of } \\
\text { Goals }\end{array}$ & $\begin{array}{l}\text { One or Two } \\
\text { (competing) }\end{array}$ & $\begin{array}{l}\text { Several } \\
\text { (limited) }\end{array}$ & Several \\
\hline $\begin{array}{l}\text { Subjective } \\
\text { Available } \\
\text { Time }\end{array}$ & Just Adequate & Adequate & Adequate \\
\hline $\begin{array}{l}\text { Selection } \\
\text { Next Action }\end{array}$ & $\begin{array}{l}\text { Association- } \\
\text { Based }\end{array}$ & Procedural & $\begin{array}{l}\text { Prediction- } \\
\text { Based }\end{array}$ \\
\hline $\begin{array}{l}\text { Evaluation } \\
\text { of Events }\end{array}$ & Concrete & $\begin{array}{l}\text { Normal } \\
\text { Details }\end{array}$ & Elaborate \\
\hline $\begin{array}{l}\text { Event } \\
\text { Horizon }\end{array}$ & Narrow & Normal & Extended \\
\hline $\begin{array}{l}\text { Plans } \\
\text { Available }\end{array}$ & Negligible or & $\begin{array}{l}\text { Available } \\
\text { and Used }\end{array}$ & $\begin{array}{l}\text { Pre- } \\
\text { Defined/ } \\
\text { Generated }\end{array}$ \\
\hline
\end{tabular}

The information provided in Table 1 also provides insights about the type of information that would be most suitable under different cognitive modes. Borrowing terms from Rasmussen [5], it can be deduced that "signals" to guide action are most suitable for opportunistic control, "signs" to trigger appropriate procedures or rules for tactical control, and "symbols" for information interpretation and integration for strategic control.

\section{USING COCOM TO DESIGN SUPPORT SYSTEM}

As describe in Section II of this paper, COCOM provides a high-order understanding of the impact that ecological constraints have on operator's behaviors. Thus, COCOM can provide designers with critical insights that can be use to design support systems that are tailored to a range of cognitive control modes; ensuring that information that the operator receives is appropriate for the current context.

\section{Design Recommendations for Opportunistic Control}

In opportunistic control, operators have very limited time, consequently they are likely to perceive information cues as "signals" and promptly react to one or two (competing) goals based upon pattern matching strategies (i.e., action are based upon association). An individual operating in an opportunistic control mode may filter out complex information and instead focus on the information that is most salient and easiest to understand. Information in the form of signals would, in this case be more helpful than information in a more complex form such as signs and symbols.

An example of this type of situation can be seen in the Three-Mile Island (TMI) incident where the accident activated the alerting system and more than 100 alarms came on in the control room. The large number of alarms overwhelmed the operator's mental resources and he was unable to distinguish relevant alarms from irrelevant alarms. While these alarms may have been appropriate for the plant state, and necessary to completely understand the situation, they were bound to push an operator into an opportunistic mode where distinguishing the most urgent or important alarm proved extremely difficult.

For opportunistic control, support system should be designed to:

- Assist in distinguishing between contextually relevant and irrelevant cues (e.g., removing or minimizing irrelevant cues from operator's view, or making key information more prominent)

- Reduce information load

- Broaden all non-critical system tolerance level (i.e., reduce false-alarm rate that can distract the operator from high priority task)

- Bringing all salient information to a single place for easy access

\section{Design Recommendations for Tactical Control}

In the tactical control mode, an operator has adequate time and mental resources to perceive the environmental cues as "signs" and attend to limited number of goals. Operators can use pattern discrimination strategies to trigger appropriate internal psychological rules (i.e., actions are procedural) as well as to determine the standard operating procedures necessary. However, moderate time and mental resources are not enough to allow an operator to elaborately assess the situation or concern himself with generating the optimal solution [6]. An example of this situation is when an off-normal event occurs and the operator is able to identify relevant cues in the environment (e.g., control dials and displays) that direct him/her to follow the correct procedure to stabilize the plant condition.

For tactical control, support system should be designed to:

- Assist the operator in computing an acceptable solution possible using established procedures

- Assist in distinguishing between contextually relevant and irrelevant cues (e.g., highlighting)

- Broaden non-critical and non-related systems tolerance level

- Clearly delineate procedural boundaries

- Make salient any information that contradicts the current procedural action 


\section{Design Recommendations for Strategic Control}

In strategic control, the operator has extended time and adequate mental resources to attend to multiple goals. At this level, the operator perceives symbols in the environment and can assess and scrutinize his/her current understanding of the environment as well as generate anticipatory plan for future events or scenarios. Strategic control also allows the operator resources necessary to obtain an optimal solution. These activities require the operator to fully and elaborately assess large quantities of information. An example of this situation is during normal operation the operator has the time and mental resources to attend to a large number of cues in the environment, to develop, assess, and revise his/her current situation awareness, as well as anticipate future possible events.

For the strategic control mode, a support system should be designed to:

- Assist the operator in computing the optimal decision solution possible along many different dimensions

- Support solution revision and iteration

- Display wide variety of information upon request to support operator situation assessment

- Maintain normal system tolerance level

\section{APPLYING COCOM TO ALARM DESIGN: AN EXAMPLE}

We now present an example of alerting system design within the nuclear control room to illustrate the usefulness of COCOM. While alerting systems play a significant role in nuclear plant operations, they pose challenges to operators who rely on them. Reference [1] listed the following deficiencies in alarm design from the literature:

- Too many alarms

- Too many false alarms

- Poor distinction between alarms and normal status indications

- Poor alarm organization

- Poor location

- Insufficient salience coding

- Inadequate message design

- Poor acoustic design

Alerting system design is further complicated by the fact that operator's role changes under different operational conditions. For example during normal operation, operators are primarily engaged in active system monitoring behaviors to support disturbance detection, situation assessment, as well as response planning, selection, and implementation [1]. An operator's monitoring behavior during nominal conditions is complex, knowledge-driven, cognitively demanding, and can be characterized as more problem-solving and planning than passive vigilance activity [9]. Furthermore, during normal condition, operators serve a supporting role in maintenance and equipment testing and repairs. During off-normal or emergency condition, an operator's primary role is to assess and implement recovery actions to stabilize plant conditions.

Three characteristics of alerting systems will be discussed here in relation to COCOM: display, processing, and availability. Alarm display is how alarms should be presented. Alarm processing refers to the process by which signals from plant sensors are automatically evaluated to determine whether any of the monitored parameters have exceeded their set points, and whether any of these deviations represented true alarms. Alarm availability refers to method by which the results of alarm processing are revealed to the operating crew (i.e., which alarms are made available).

TABLE 2. SUMMARY OF ALARM DESIGN USING COCOM

\begin{tabular}{|l|l|l|l|}
\hline $\begin{array}{l}\text { Alarm } \\
\text { Features }\end{array}$ & $\begin{array}{l}\text { Opportunistic } \\
\text { Control } \\
\text { (off-normal } \\
\text { emergency) } \\
\text { High Workload }\end{array}$ & $\begin{array}{l}\text { Tactical } \\
\text { Control } \\
\text { (off-normal } \\
\text { condition) } \\
\text { Moderate } \\
\text { Workload }\end{array}$ & $\begin{array}{l}\text { Strategic } \\
\text { Control } \\
\text { (normal } \\
\text { condition) } \\
\text { Low Workload }\end{array}$ \\
\hline $\begin{array}{l}\text { Alarm } \\
\text { Display }\end{array}$ & Alarm Tile & $\begin{array}{l}\text { Process } \\
\text { Display }\end{array}$ & $\begin{array}{l}\text { Alarm List } \\
\text { Display }\end{array}$ \\
\hline $\begin{array}{l}\text { Alarm } \\
\text { Processing }\end{array}$ & Very conservative & $\begin{array}{l}\text { Conservative } \\
\text { set point }\end{array}$ & $\begin{array}{l}\text { Liberal set } \\
\text { point }\end{array}$ \\
\hline $\begin{array}{l}\text { Alarm } \\
\text { Availability }\end{array}$ & Alarm filtering & $\begin{array}{l}\text { Alarm } \\
\text { Suppression }\end{array}$ & $\begin{array}{l}\text { Alarm } \\
\text { prioritization }\end{array}$ \\
\hline
\end{tabular}

Table 2 summarizes alarm design using COCOM. Designers can develop different display mode within each control mode of which the operator can select the appropriate display mode that is consistent with the environmental demands.

\section{$\underline{\text { Normal Condition }}$}

During normal conditions with low workload and/or low time pressure, operators are likely to engage in strategic control. Alarms should be presented using list display which provides detail information about the alarm to the operator (See Figure 2). 


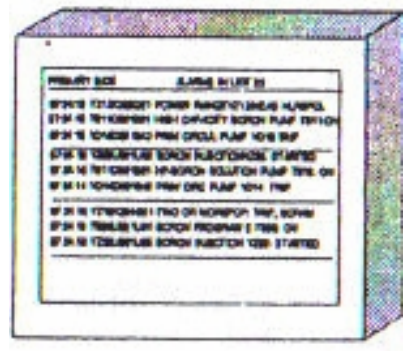

Figure 2. Alarms in list display format.

Alarm processing (i.e., set-point) should be set close to normal operating value or within normal parameter drift. Such liberal threshold criteria will provide early alert to operator of a potential disturbances. Alarm availability should be based upon alarm ranking technique on some dimension and be presented in a way to convey their importance. Given the extended time and high mental resources, alarms design in strategic control mode support operators reliance on sampling strategies based upon successive observations of wide variety of weakly related variables to analytically assess current condition as well as project and plan future plan conditions.

\section{Off-Normal Condition}

During off-nominal conditions with moderate workload and/or moderate time pressure, operators are likely to shift away from a strategic control mode toward a tactical control mode. Alarms should be presented using process display which provides a good understanding of relationship between different alarms and disturbances (See Figure 3).

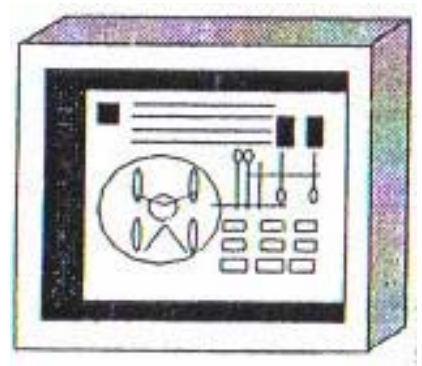

Figure 2. Alarms in process display format.

Alarm processing should be set further away from normal operating value for more conservative threshold criteria to reduce the number of irrelevant and/or false alarms. Alarm availability should be based upon alarm suppression techniques so that alarms determined to be superseded, irrelevant, or otherwise unnecessary are not presented to the operators. Non-critical alarms should be indirectly indicated and accessible upon operator upon request. Given moderate time and modest mental resources, alarm design in tactical control mode should encourage operators to rely on more appropriate sampling strategy of correlated variables, which should in turn facilitates the detection, recognition, and action of a system or component failure

\section{Off-Normal/Emergence Condition}

During off-normal/emergency conditions with high workload and/or high time pressure, operators are likely to shift towards opportunistic control mode. In these events, alarms should be presented using displays that are similar to tile displays for quick recognition (i.e., operators can use the tile display's spatial organization for quick response; See Figure 4).

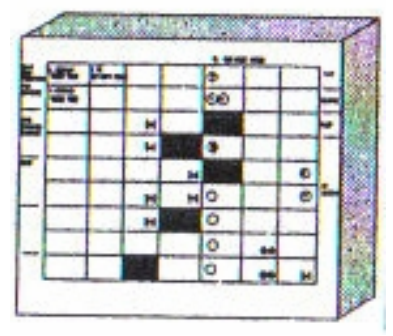

Figure 4. Alarms in tile display format.

Alarm processing should be set very conservatively to reduce information load (e.g., prevent irrelevant and false alarms). Alarm availability should be based upon alarm filtering technique so that alarms determined by processing techniques to be less important, irrelevant, or otherwise unnecessary are eliminated and are not available to the operators. Given just adequate time and low mental resources, alarm design in opportunistic control mode should keep information load as low as possible to prevent operators to adopt inappropriate alarmsampling strategies, making the accurate diagnosis of system anomalies less likely.

\section{CONCLUSIONS}

Nuclear power plant operator's environment has been characterized as "hours of intolerable boredom punctuated by a few minutes of pure hell" [7, p508]. This statement illustrates the roller-coaster of mental states an operator experiences between normal, off-normal, and emergency operating conditions. To cope with these different operation conditions, operators rely on different cognitive strategies and processes that are specifically fit to different 
environmental demands. Thus, it is important that system are designed to be sensitive to the different cognitive control mode to ensure that operators obtain the necessary information needs (i.e., information types as well as amount of information) to ensure plant safety. This paper presented an example with alarm system design to demonstrate how COCOM can be use in control room operation design. It argues that designing alarm systems to accommodate a range of operator cognitive modes will be of great benefit as the nuclear industry continues to upgrade their current technology for next generation control room design which is forecast to be more computerized, intelligent, integrated, and automated.

\section{DISCLAIMER}

This paper was prepared as an account of work sponsored by an agency of the United States Government. Neither the United States Government nor any agency thereof, nor any of their employees, makes any warranty, expressed or implied, or assumes any legal liability or responsibility for any third party's use, or the results of such use, of any information, apparatus, product, or process disclosed in this paper, or represents that its use by such third party would not infringe privately owned rights.

\section{REFERENCES}

[1] O'Hara, J., Brown, W., Hallbert, B., Skråning, G., Wachtel. J., and Persensky, J., the Effects of Alarm Display, Processing, and Availability on Crew Performance (NUREG/CR-6691). Washington, D.C.: U.S. Nuclear Regulatory Commission, 2000.

[2] Hammond, K.R. Introduction to Brunswikian theory and methods. In K.R. Hammond andN.E. Wascoe (Eds.), Realizations of Brunswik's experimental design. San Francisco: Jossey-Bass, 1980.

[3] Hollnagel, E., Cognitive Reliability and Error Analysis Method (CREAM), Elsevier, Oxford, 1998.

[4] Klein, G. A recognition-primed decision (RPD) model of rapid decision-making. In G.Klein, J. Orasanu, R. Calderwood, and C.E. Zsambok (Eds.), Decision-making in action:Models and methods (pp. 138-147). Norwood, NJ: Ablex, 1993.

[5] Rasmussen, J. Skills, rules, knowledge: Signals, signs, and symbols and otherdistinctions in human performance models. IEEE Transactions on Systems, Man, and Cybernetics, 13(3),1983, pp. 257-267.

[6] Elgin, P.D., \& Thomas, R.P. An integrated decision-making model for categorizing weather products and decision aids. Technical Report NASA/TM-2004-212990, National Aeronautics and Space Administration, Langley Research Center, Hampton, Virginia, 2004.

[7] Wickens, C. D., Lee, J. D., Liu, Y., \& Gordon Becker, S. E., An Introduction to Human Factors Engineering, $\left(2^{\text {nd }}\right.$ Ed.), New Jersey, Prentice Hall, 2004.

[8] Hollnagel, E. Human reliability analysis: Context and control, Academic Press, London, UK, 1993.
[9] Mumaw, R.J., Roth, E.M., Vicente, K.J., \& Burns, C.M. There is more to monitoring a nuclear power plant than meets the eye. Human Factors, 41(1), 2000, pp.36-55. 